\title{
Planejamento e controle em sistema integrado de produção agrícola do cerrado mato-grossense
}

\author{
Planning and control in an integrated agricultural production system in the Cerrado \\ of Mato Grosso
}

\author{
Patrícia Souza Costa ${ }^{a}$ \\ Taire da Silva Ribeiro ${ }^{b}$ \\ Liz Vanessa Lupi Gasparini ${ }^{c}$ \\ Adelice Minetto Sznitowski ${ }^{d}$
}

\begin{abstract}
Resumo: Sistemas integrados de produção agrícola (SINPA) têm gerado ganhos financeiros, sociais e ambientais, mas necessitam de gestão integrada. Este estudo de caso explora o planejamento e o controle da produção (PCP) em uma empresa rural do cerrado mato-grossense, analisando tecnologias, processos produtivos e resultados dos sistemas integrado e convencional. Os resultados demonstram que o SINPA exigiu tecnologias, aumentou a produtividade da lavoura e permitiu incentivos fiscais à floresta. Apesar de o sistema produtivo ser integrado, seu PCP é realizado separadamente, o que prejudica obter ganhos de otimização. O PCP integrado pode aprimorar este sistema produtivo estratégico ao desenvolvimento rural e do agronegócio. A gestão de empresas rurais precisa avançar, em busca de rentabilidade, tecnologias de gestão de recursos e de processos capazes de gerá-la.
\end{abstract}

Palavras-chave: Gestão da Produção; Mudança tecnológica; Inovação; Agropecuária. Classificação JEL: M11; O33; O13

\begin{abstract}
Integrated agricultural production systems (IAPS) suffer financial, social and environmental investments, but need to use integrated management. This case study explores production planning and control (PPC) in a rural company in the Cerrado of Mato Grosso, analyzing technologies, productive processes and results in integrated and conventional systems. The results demonstrated that IAPS require technologies, increased crop productivity and allowed tax incentives in the forest. Despite the productive system being integrated, its PPC is executed specified, which does not allow to obtain gains in the optimization of productive. The PPC can improve this strategic system for rural and agribusiness development. In the rural context, management needs to move forward, in search of profitability, resource management technologies and processes capable of generating.
\end{abstract}

Keywords: Production Management; Technological change; Innovation; Agriculture.

\footnotetext{
${ }^{\text {a }}$ Graduada em Administração - UNEMAT. E-mail: patricia_scg@ hotmail.com.

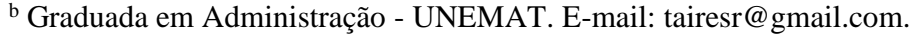

${ }^{\mathrm{c}} \mathrm{Dr}^{\mathrm{a}}$, Professora adjunta no Curso de Administração na UNEMAT. E-mail: lizvanessa@unemat.br

${ }^{\mathrm{d}} \mathrm{Dr}^{\mathrm{a}}$, Professora adjunta no Curso de Administração na UNEMAT. E-mail: adelice.minetto@ unemat.br
} 


\section{Introdução}

A atividade produtiva no campo é de alto risco e não existe um padrão de gestão estabelecido (DAVIS; GOLDBERG, 1957; NOBRE; OLIVEIRA, 2018). Isto constitui um dos desafios para tomadores de decisão: compreender a grandiosidade que transforma o peso da 'agricultura' em 'agronegócio', e os 'problemas agrícolas' em 'problemas empresariais', sendo "[...] inevitáveis mudanças inerentes à inclusão de tecnologias, aumento de unidades, organização, competência gerencial, conhecimento técnico, necessidade de capital e potencial de mercado" (DAVIS; GOLDBERG, 1957, p. 173).

O sistema produtivo deve se alinhar à estratégia organizacional, e seu planejamento e controle "[...] pode ser visto como parte de um processo que coordena os objetivos e metas operacionais com objetivos mais amplos das organizações" (CHASE; AQUILANO; JACOBS, 2006, p. 38). No caso da agricultura, a decisão está na escolha das culturas, tecnologias e práticas agrícolas, exigindo conhecimento técnico e gerencial. No contexto atual, conhecimento e experiência já não são suficientes para um bom desempenho no campo. "A atividade necessita de práticas de gestão capazes de planejar e monitorar sistematicamente o desempenho técnico e econômico" (NOBRE; OLIVEIRA, 2018, p178).

Dentre os tipos de sistemas produtivos agrícolas e que constituem inovação tecnológica, estão os sistemas integrados de produção agrícola sustentáveis (SINPA), que apresentam quatro modalidades de integração: 1) lavoura-pecuária (ILP); 2) pecuáriafloresta (IPF); 3) lavoura-floresta (ILF); e, 4) lavoura-pecuária-floresta (ILPF). Devido à sua complexidade, pelo fato de integrar os componentes vegetais e animais, a ILPF requer planejamento, e a sua execução requer infraestrutura produtiva, capacidade de armazenamento, recursos financeiros, acesso ao crédito, domínio de tecnologia para a produção, comercialização, melhor uso de recursos e de arranjo de culturas, e viabilidade econômica (BALBINO et al., 2011, p. 3-5).

Por outro lado, a gestão derivada do planejamento e do controle da produção (PCP) em sistemas produtivos é essencial para avaliar o desempenho e verificar se objetivos propostos foram atingidos em todos os processos. Além de tecnologias de produção presentes nos sistemas integrados de produção agrícola, o desempenho de empresas rurais depende igualmente de tecnologias de gestão, como o PCP (GASPARINI; COSTA; SZNITOWSKI, 2018, p. 03-04). A “[...] agricultura para a sustentabilidade exige abordagem holística para planejamento e gestão agrícola [...]" (IKERD, 1993, p. 155). Entraves de gerenciamento nas empresas rurais no Brasil significam claramente a falta de PCP (NOBRE; OLIVEIRA, 2018, p. 179).

Diante do contexto apresentado, o estudo parte do pressuposto que em face da complexidade dos sistemas integrados de produção, o planejamento e o controle integrado da produção podem ser utilizados para melhor gerir tais processos produtivos.

Abordagens deste escopo são pertinentes ao se considerar a representatividade do estado de Mato Grosso, cuja economia é movida pela agropecuária, e possui 1,5 milhão de hectares (ha) em ILPF, sendo 90 \% ILP, 6 \% ILPF e 4 \% IPF, e dez unidades de referência 
tecnológica econômica (URTE), assistidas pela Empresa Brasileira de Pesquisa Agropecuária (Embrapa) (EMBRAPA, 2017).

Menciona-se também a complexidade da gestão de sistemas integrados de produção agrícola, o que motivou este estudo a explorar o PCP no SINPA/ILPF em uma empresa rural mato-grossense. Para tanto, foram comparadas as tecnologias aplicadas e os resultados obtidos do sistema integrado de produção com o sistema convencional anterior à sua adoção. Foram levantados os processos produtivos das atividades realizadas e analisado como o PCP é praticado. O local - objeto deste estudo - foi pioneiro na implantação de SINPA na modalidade ILPF, tornando-se referência para produtores que desejam implantá-lo na região. Por isso a relevância de abordar o PCP em um contexto de ILPF, contribuindo para decisões mais assertivas no âmbito das empresas rurais.

Este artigo está dividido em cinco seções, além desta introdução. Na próxima seção apresenta-se o referencial teórico do PCP e do SINPA. Na terceira seção, descritos os procedimentos metodológicos utilizados neste estudo. Na quarta seção são analisados e discutidos os resultados obtidos. Por fim, são apresentadas considerações finais.

\section{Referencial Teórico}

\subsection{Planejamento e controle da produção (PCP)}

O planejamento e o controle da produção é uma tecnologia de gestão que permite aos gestores ter uma maior previsão e controle sobre todas as atividades relacionadas ao sistema produtivo em execução ou a serem executadas, o que inclui: o que será produzido, onde, em que volume, em que sequência e a alocação dos recursos (SLACK; CHAMBERS; JOHNSTON, 2009, p. 313). Para realizar o planejamento e o controle da produção é fundamental seguir algumas etapas estratégicas, definidas no quadro 1.

O PCP deve se estender a todos os processos existentes, visto que contribui para sua gestão eficiente, permitindo minimizar ou eliminar falhas. Este olhar da gestão de processos contribui com o PCP pela clareza em suas etapas: carregamento, sequenciamento e programação, monitoramento, mensuração, avaliação e intervenção de cada atividade para eliminar custos e desperdícios, e o uso correto de cada recurso disponível, além da efetividade na execução de tarefas (GASPARINI; COSTA; SZNITOWSKI, 2018).

Em empresas rurais os gestores devem trabalhar com o PCP de acordo com o produto agropecuário oferecido, além de considerarem como produzir, quais recursos naturais a utilizar e como minimizar impactos no meio ambiente, entre outras decisões como a melhor estratégia para a comercialização, sazonalidade, utilização de recursos operacionais, humanos, financeiros e naturais (LOPES et al., 2012). Para elaborar o PCP, o gestor rural deve observar fatores internos (tamanho da propriedade, rendimento de cultivos/criações, produtividade, seleção e combinação de atividades produtivas, eficiência de manejo e pessoal) e externos (preço de produtos e clima: histórico e tendência, existência de mercado, política de crédito e financiamento, logística e disponibilidade de pessoal) (NOBRE; OLIVEIRA, 2018, p. 180). 
Quadro 1 - Etapas do Planejamento e Controle da Produção por fase

\begin{tabular}{|c|c|}
\hline FASE & $\begin{array}{l}\text { ETAPAS DO PLANEJAMENTO E CONTROLE DA PRODUÇÃO } \\
(\text { PCP) }\end{array}$ \\
\hline \multirow{3}{*}{ PLANEJAMENTO } & $\begin{array}{l}\text { CARREGAMENTO: quantidade de trabalho destinado para um centro } \\
\text { de trabalho, capacidade de produção }\end{array}$ \\
\hline & SEQUENCIAMENTO: ordem em que as tarefas serão executadas \\
\hline & PROGRAMAÇÃO: quando as atividades deveriam começar e terminar \\
\hline \multirow{4}{*}{ CONTROLE } & $\begin{array}{l}\text { MENSURAÇÃO: combinação sistemática de ferramentas /métricas } \\
\text { utilizadas para qualificar e quantificar a eficiência e /ou eficácia de uma } \\
\text { ação }\end{array}$ \\
\hline & $\begin{array}{l}\text { MONITORAMENTO: acompanhamento } \\
\text { desenvolvimento da atividade }\end{array}$ \\
\hline & $\begin{array}{l}\text { AVALIAÇÃO: julgamento do desempenho medido: se é bom, mal ou } \\
\text { insignificante }\end{array}$ \\
\hline & $\begin{array}{l}\text { INTERVENÇÃO: ajustes para que a operação atinja objetivos } \\
\text { estabelecidos pelo plano inicial }\end{array}$ \\
\hline
\end{tabular}

Fonte: Adaptado de Slack, Chambers e Johnston (2009).

Em sistemas integrados, sobretudo de produção agropecuária, a relevância de delinear o PCP aumenta, especialmente na ILPF, por possuir três processos produtivos resultantes de cada atividade: lavoura, pecuária e floresta. Além da complexidade para a integração destes processos, destaca-se ainda que as organizações rurais são "fábricas à céu aberto" (OSAKI, 2012), sujeitas a especificidades produtivas que exigem mais do gestor para alcançar objetivos planejados e minimizar seus impactos nos resultados (BUANAIN, 2007), o que reforça a importância do PCP no âmbito das empresas rurais.

\subsection{Sistemas integrados de produção agrícola (SINPA): integração lavoura-pecuária-floresta (ILPF) e seus processos produtivos}

A crescente demanda mundial por produção sustentável leva a inovações produtivas, dentre as quais destacam-se os sistemas integrados de produção agrícola por gerarem benefícios ambientais, econômicos e sociais. Esta alternativa tecnológica em expansão é definida como um sistema de produção sustentável porque promove recuperação de pastagens em degradação e melhora as propriedades químicas, físicas e biológicas do solo. Apresenta-se economicamente viável pois permite o uso mais eficiente dos equipamentos e o aumento de emprego e renda no campo (BALBINO et. al, 2011, p.3).

Por apresentar elevada sinergia, já que uma espécie influencia a outra num mesmo espaço físico derivado de sistemas de sucessão, rotação, consorciação ou integração (HIRAKURI et al., 2012), "os sistemas integrados surgem como alternativa ambiental para o bom uso e recuperação da terra e tendem a oferecer alternativas ás questões sociais, ambientais e econômicas" (BALBINO et. al, 2011, p. 4). 
SINPAs podem ser entendidos como a integração de sistemas de cultivo e/ou criação de diferentes finalidades na mesma área, para maximizar o uso da terra e dos meios de produção e para diversificar a renda. Este sistema produtivo abrange quatro modalidades: 1) integração lavoura-pecuária (ILP): integrando agricultura e pecuária em rotação, consórcio ou sucessão na mesma área e em um mesmo ano agrícola ou por múltiplos anos; 2) integração pecuária-floresta (IPF): reunindo pecuária e floresta em consórcio; 3) integração lavoura-floresta (ILF): combinando floresta e agricultura, pelo consórcio de espécies arbóreas com cultivos agrícolas (anuais ou perenes); e 4) integração lavourapecuária-floresta (ILPF): integrando agricultura, pecuária e floresta em rotação, consórcio ou sucessão na mesma área, sendo considerado o modelo mais complexo (HIRAKURI et al., 2012; EMBRAPA, 2016).

Nos sistemas integrados, para maior eficiência produtiva, o gestor necessita integrar os processos produtivos da lavoura, pecuária e/ou floresta no PCP de forma a utilizar cada recurso de maneira eficiente, efetivando o processo integrado (IKERD, 1993; RUSSELLE; ENTZ; FRANZLUEBBERS, 2007; SULC; TRACY, 2007, BUNGESNSTAB, 2014). Neste contexto, tais modelos revelam uma produção multiproduto, em que a premissa é aumentar o número de safras anuais, reduzir custos fixos, em especial, os custos de máquinas e mão de obra (OSAKI, 2012). Em cada um dos três processos produtivos (da lavoura, pecuária e/ou floresta) é preciso considerar a diversidade de recursos necessários e, por vezes, a concorrência entre eles.

O processo produtivo da lavoura compreende: captação de recursos financeiros, arrendamentos, aquisição de insumos, contratação de mão de obra (ou seja, o pré plantio); forragem, calagem, aplicação de gesso no solo, adubação de superfície, de invasoras, aragem, gradagem, subsolagem (ou seja, o preparo do solo); semeadura, aplicação de adubo básico (ou seja, o plantio); pulverização de defensivos, adubação de cobertura e foliar, capina mecânica foliar (ou seja, os tratos culturais); colheita e destruição de soqueiras (ou seja, a colheita); beneficiamento, comercialização, liberação de vendas antecipadas e transporte da produção (ou seja, o pós colheita) (ARAÚJO, 2009). O processo da floresta engloba: sulcagem e coveamento (ou seja, o preparo do solo); aplicação de formicida, inseticida, desbaste, desrama (ou seja, o trato cultural); vendas de crédito ou reposição de carbono (ou seja, o pós colheita) (REMADE, 2003). O processo da pecuária inclui: construção de currais, cercas e bebedouros, desvermifugação, marcação, vacinação, pesagem, separação de lotes, rotação e roçada de pastos, desmama e cuidados veterinários e assistência técnica (ou seja, a cria); marcação, vacinação, separação de lotes, sal, desmana, castração, engorda e cuidados veterinários e assistência técnica (ou seja, a recria); marcação, vacinação, pesagem, rotação de pastos, semi confinamento, fertilizantes e produtos veterinários, sal, rações, cuidados veterinários e assistência (ou seja, a engorda); embarque (ou seja, o pós criação) (ARAÚJO, 2009).

Por meio da integração destes processos produtivos, a ILPF modifica o sistema de uso do solo para atingir resultados cada vez mais elevados de qualidade do produto, proteção ambiental, produtividade e competitividade. Logo, as vantagens da adoção deste sistema são: aumento da qualidade ou melhoria dos atributos do solo; recuperação de áreas 
degradadas; diminuição da ociosidade do uso das áreas agrícolas; diversificação da produção; estabilização da renda na propriedade rural; quebra do ciclo de doenças; redução de pragas e insetos e de plantas daninhas; melhora do ambiente, do desempenho animal e do solo (BRASIL, 2016, EMBRAPA, 2018).

As dificuldades para a adoção da ILPF se iniciam pela necessidade de amplos estudos sobre a viabilidade econômica dos diferentes arranjos, das políticas públicas para investimentos iniciais, dos conhecimentos tecnológicos e da capacitação de profissionais multidisciplinares (BALBINO et al., 2011, BUNGESNSTAB, 2014). Neste sentido, barreiras para o sucesso são adequação de infraestrutura, mão de obra especializada nas três atividades, e práticas de manejo diferentes da tradicional monocultura (SULC; TRACY, 2007; RUSSELLE; ENTZ; FRANZLUEBBERS, 2007; BALBINO et al., 2011). Além do mais, existem dificuldades financeiras e de gestão como alto investimento inicial, pouco incentivo governamental, falta ou dificuldade de acesso a informações, problemas na qualificação de pessoal estratégico, tático e operacional, e elevada complexidade de planejar e controlar a produção combinada (GASPARINI et al., 2017; GASPARINI; COSTA; SZNITOWSKI, 2018). Isto tudo, corrobora o fato de que os recursos concorrem entre os sistemas da integração, principalmente, os recursos humanos (RUSSELLE; ENTZ; FRANZLUEBBERS, 2007).

A aproximação do agricultor e do pesquisador pode potencializar estudos de como desenvolver e gerenciar sistemas integrados de produção (SULC; TRACY, 2007), pois a agricultura sustentável baseia-se em um modelo de desenvolvimento que percebe unidades de produção de sistemas compostos por subsistemas inter-relacionados e complexos, com limites físicos, biológicos e sociais distintos, que requerem conhecimento além do agronômico para o êxito da integração (IKERD, 1993).

\section{Procedimentos metodológicos}

A pesquisa baseou-se em dados qualitativos por meio de estudo de caso exploratório e descritivo (YIN, 2010), desenvolvido em uma empresa rural para entender como funciona o PCP no SINPA de forma a compreender as tecnologias, os resultados, os processos produtivos, e o seu planejamento e controle. A unidade de análise compreende o PCP do SINPA de uma empresa rural localizada no bioma Cerrado, no estado de Mato Grosso (INSTITUTO MATOGROSSENSE DE ECONOMIA PECUÁRIA, 2017).

Foram realizadas pesquisas documental e de campo. A pesquisa de campo se deu por questionário e entrevista semiestruturada individuais in loco com o gestor da integração e da floresta e o gerente de campo responsável pela lavoura. Os gerentes da pecuária e floresta não responderam por alegarem desconhecer o planejamento das atividades $\mathrm{A}$ pesquisa documental levantou a existência, o conteúdo e o uso de planejamentos e controles manuais ou sistematizados, como registros de atividades e de produtividade de safras da propriedade. Logo, foram coletados dados como: a) as tecnologias aplicadas e os resultados obtidos no SINPA e no sistema convencional anterior à adoção; b) os processos produtivos 
das atividades realizadas no SINPA; e, c) as etapas do PCP do SINPA, estruturadas por categorias e elementos de análise do PCP para SINPA (ver quadro 2).

Quadro 2 - Categorias e elementos de análise do PCP para sistemas integrados agropecuários

\begin{tabular}{|c|c|c|}
\hline $\begin{array}{l}\text { CONS } \\
\text { TRU } \\
\text { TOS }\end{array}$ & $\begin{array}{l}\text { CATEGORIAS } \\
\text { DE ANÁLISE }\end{array}$ & ELEMENTOS DE ANÁLISE \\
\hline \multirow{3}{*}{$\sum_{\substack{\mid \\
\sum_{0}}}^{0}$} & $\begin{array}{l}\text { CARREGA- } \\
\text { MENTO } \\
\text { Slack, Chambers e } \\
\text { Johnston (2009) }\end{array}$ & $\begin{array}{l}\text { - Recursos para o processo produtivo (terra, maquinário, } \\
\text { pessoas) } \\
\text { - Tempo (inicial, atual, futuro) } \\
\text { - Critério ideal (ou combinação) de objetivos de desempenho: } \\
\text { rentabilidade, diversificação de renda, sustentabilidade, outros } \\
\text { - Responsável }\end{array}$ \\
\hline & $\begin{array}{l}\text { SEQUENCIA- } \\
\text { MENTO } \\
\text { Slack, Chambers e } \\
\text { Johnston (2009) }\end{array}$ & $\begin{array}{l}\text { - Sequência normal das atividades produtivas LPF } \\
\text { - Demandas do processo produtivo integrado: recursos que } \\
\text { concorrem entre si (terra, máquinas, pessoas, outros) } \\
\text { - Prioridades do SINPA em caso de demandas concorrentes } \\
\text { - Responsável }\end{array}$ \\
\hline & $\begin{array}{l}\text { PROGRA- } \\
\text { MAÇÃO } \\
\text { Slack, Chambers e } \\
\text { Johnston (2009) }\end{array}$ & $\begin{array}{l}\text { - Cronograma de cada atividade produtiva: LPF em cada etapa } \\
\text { do processo produtivo (pre-plantio, semeio, ...) } \\
\text { - Onde inicia e termina cada atividade e suas etapas } \\
\text { - Responsável }\end{array}$ \\
\hline \multirow{4}{*}{ 量 } & $\begin{array}{l}\text { MENSURAÇÃO } \\
\text { Neely, Gregory e } \\
\text { Platts (1995) } \\
\end{array}$ & $\begin{array}{l}\text { - Métrica usada para quantificar (indicadores de desempenho) } \\
\text { - Qualificar eficiência e/ou eficácia da ação } \\
\text { - Responsável }\end{array}$ \\
\hline & $\begin{array}{l}\text { MONITORA- } \\
\text { MENTO } \\
\text { Slack, Chambers e } \\
\text { Johnston (2009) } \\
\end{array}$ & $\begin{array}{l}\text { - Acompanhamento sistemático (existe, periodicidade) } \\
\text { - Registros (existem, formato) } \\
\text { - Responsável }\end{array}$ \\
\hline & $\begin{array}{l}\text { AVALIAÇ̃̃̃O } \\
\text { Slack, Chambers e } \\
\text { Johnston (2009) } \\
\end{array}$ & $\begin{array}{l}\text { - Eleger e comparar a um padrão, Identificar desvios (tipos: } \\
\text { histórico, alvo, concorrência, absoluto) } \\
\text { - Responsável }\end{array}$ \\
\hline & $\begin{array}{l}\text { INTERVENÇÃO } \\
\text { Slack; Chambers; } \\
\text { Johnston (2009), } \\
\text { Cury (2017) }\end{array}$ & $\begin{array}{l}\text { - Tempo para decidir a ação de intervenção } \\
\text { - Responsável }\end{array}$ \\
\hline
\end{tabular}

Fonte: Gasparini, Costa e Sznitowski (2018).

Com base na descrição dos processos das atividades produtivas, suas etapas foram lançadas no gráfico de Gantt para integrá-las. Foi utilizado o software Gantt Project, que permite inserir atividades e as suas respectivas datas. O diagrama de Gantt mostra início, fim e duração de cada tarefa a ser realizada, sendo considerado o gráfico de PCP (SLACK; CHAMBERS; JOHNSTON, 2009). 
A análise dos dados foi realizada: a) comparando resultados e tecnologias aplicadas nas atividades do SINPA e do sistema convencional, para observar sua evolução/involução; b) identificando sobreposições de atividades para identificar recursos concorridos no SINPA e seus impactos; e, c) à luz da teoria de PCP, considerando seus elementos (quadro 2), para conhecer como as atividades do SINPA são planejadas (carregadas, sequenciadas e programadas) e controladas (mensuradas, monitoradas, avaliadas e ajustadas), e dos critérios de prioridade estratégicas: custo, qualidade, flexibilidade, velocidade, confiabilidade (SLACK; CHAMBERS; JOHNSTON, 2009), rentabilidade, diversificação de renda e/ou sustentabilidade do negócio.

\section{Resultados e discussão}

\subsection{Tecnologias aplicadas e resultados no SINPA e no convencional}

A empresa rural mato-grossense pesquisada possui uma área de 3.025 hectares. Suas atividades iniciaram com lavoura no sistema convencional, em 2007, ocupando 1.446 hectares e, em 2011, integrou lavoura-floresta e, em 2012, incluiu a pecuária em 2.146 hectares destinados à ILPF. Contudo, as informações sobre a pecuária não foram fornecidas durante a pesquisa de campo.

$\mathrm{Na}$ lavoura, as principais culturas são soja (primeira safra) e milho (segunda safra). No sistema convencional, produzia cerca de 45 sacas por hectare ( $\mathrm{scs} / \mathrm{ha}$ ) de soja, e no sistema ILPF essa produção foi para $55 \mathrm{scs} /$ ha. Na segunda safra, produzia em média 80 scs/ha. de milho e na ILPF passou a produzir $100 \mathrm{scs} / \mathrm{ha}$. Assim, sem ampliar a área plantada, a quantidade de sacas colhidas aumentou $22 \%$ e $25 \%$, respectivamente.

A adesão ao sistema integrado provocou a adoção de tecnologias de produção na lavoura: plantio direto, agricultura de precisão, aplicações individuais e localizadas de calcário e adubo conforme o mapa de fertilidade do solo e variedades mais produtivas de milho. A cobertura do solo com braquiária, disseminada na ILPF por recuperar o solo, contribuiu para o aumento da produção de grãos. Houve investimento em maquinários para lavoura e floresta e foram contratados gerentes de campo para cada uma das três atividades.

$\mathrm{Na}$ floresta, a espécie que predomina é o eucalipto. Houve mudança da tecnologia de espaçamento e escolha da espécie na transição para o sistema integrado. No modelo convencional, a área plantada era 30 ha adensada, e no integrado foi ampliada para 500 ha com árvores e linhas mais espaçadas. As variedades do convencional foram testadas e a que apresentou melhor adaptação ao solo, mais resistência e crescimento foi plantada na área de integração. As demais tecnologias do sistema convencional foram mantidas no sistema integrado. Desde quando produzia pelo sistema convencional, a empresa possui assessoria especializada para auxiliar nos cuidados com o eucalipto. Os custos foram os mesmos para os dois sistemas, em média R \$2.450,00/ha para implantar e R \$ 2.000,00/ha na manutenção. No sistema integrado, ocorreu o recebimento de incentivos fiscais devido à reposição florestal. 
Os principais benefícios percebidos no SINPA foram: diversificação da renda; redução de risco econômico e aumento da produtividade/ha, resultantes da recuperação do solo, retenção de água e fornecimento de mais nutrientes à planta, corroborando os estudos de Russelle, Entz e Franzluebbers (2007) e da ILPF em URTEs (BRASIL, 2016; EMBRAPA, 2018). O gestor pretende aumentar a área de integração futuramente devido aos bons resultados. No entanto, a pesquisa de campo apontou que a mão de obra e os maquinários são divididos por atividade e não concorrem entre si, por este motivo não se confirmou o aumento da eficiência no uso do pessoal e dos recursos produtivos.

Os principais obstáculos para a integração dos sistemas produtivos na empresa rural em questão ocorreram no início da implantação devido à falta de preparo da equipe, dificuldade de planejar e escalonar as atividades produtivas e concorrência de recursos, o que foi constatado também por Ikerd (1993), Sulc e Tracy (2007) e Russelle, Entz e Franzluebbers (2007). O investimento inicial demandado foi alto e houve dificuldade em alocar recursos para tal modernização. O retorno dos investimentos é de longo prazo e a falta de informações sobre a viabilidade econômica da integração elevou os custos. Em relação às linhas de créditos disponíveis, foi utilizada apenas a linha de crédito de reposição florestal. O gestor tentou obter crédito na linha Agricultura de Baixo Carbono (BUNGENSTAB, 2012) mas teve dificuldades devido ao excesso de burocracia.

Observa-se que os altos investimentos e a falta de informações para implantação que elevaram os custos da empresa analisada derivaram da aquisição de maquinário e da contratação de pessoal exclusivo para cada uma das atividades - o que foge do princípio de sistemas integrados de potencializar/aproveitar os mesmos recursos produtivos em diferentes atividades (RUSSELLE; ENTZ; FRANZLUEBBERS, 2007; EMBRAPA, 2018). Tais entraves poderiam ter sido evitados com o PCP formalizado de cada atividade e, sobretudo, do integrado, pois antes de iniciar as atividades o gestor saberia os recursos concorrentes e como poderiam ser otimizados, quais valores a serem investidos e quais os prazos de retorno, minimizando o risco do método de tentativa e erro adotado pela empresa analisada. Apesar de esta prática produtiva não ser tão adotada no estado do Mato Grosso, existem consideráveis informações disponíveis que permitem delinear sistemas integrados de produção agrícola, mas isto exige qualificação do pessoal nos níveis estratégico e tático, uma dificuldade apontada pela pesquisa de campo (IKERD, 1993, RUSSELLE, 2007, BUNGENSTAB, 2012, GASPARINI et al., 2017). O delineamento do PCP exige conhecer etapas dos processos produtivos, recursos utilizados, seus executores e datas de início e término, e pode ser realizado usando o gráfico de Gantt (BUNGENSTAB, 2012).

\subsection{Processos produtivos do SINPA}

A partir dos dados coletados foi possível delinear a programação integrada da lavoura e da floresta no gráfico de Gantt (ver figura 1). Por falta de dados da pecuária não foi possível programar as três atividades integradas. Este gráfico possibilita, por meio de barras que representam o tempo, visualizar o caminho crítico de determinado processo ou 
atividade, e perceber a dependência entre esses processos e os gargalos na estrutura e na divisão das tarefas (SLACK; CHAMBERS; JOHNSTON, 2009, p. 244).

As etapas dos processos aplicadas na empresa rural e representadas no Gantt são menos detalhadas que as etapas sugeridas na literatura para lavoura e floresta. O gestor defende que as etapas executadas são as necessárias para alcançar a produtividade destacada, e que conforme análises de cada safra, tais etapas são acrescidas ou retiradas do processo. Isto confirma que não existe um padrão a executar, cada PCP será elaborado de acordo com análises do ambiente interno e externo da propriedade rural (EMBRAPA, 2017; NOBRE; OLIVEIRA, 2018).

\section{Figura 1 - Programação integrada da produção da lavoura e da floresta do SINPA da empresa rural}

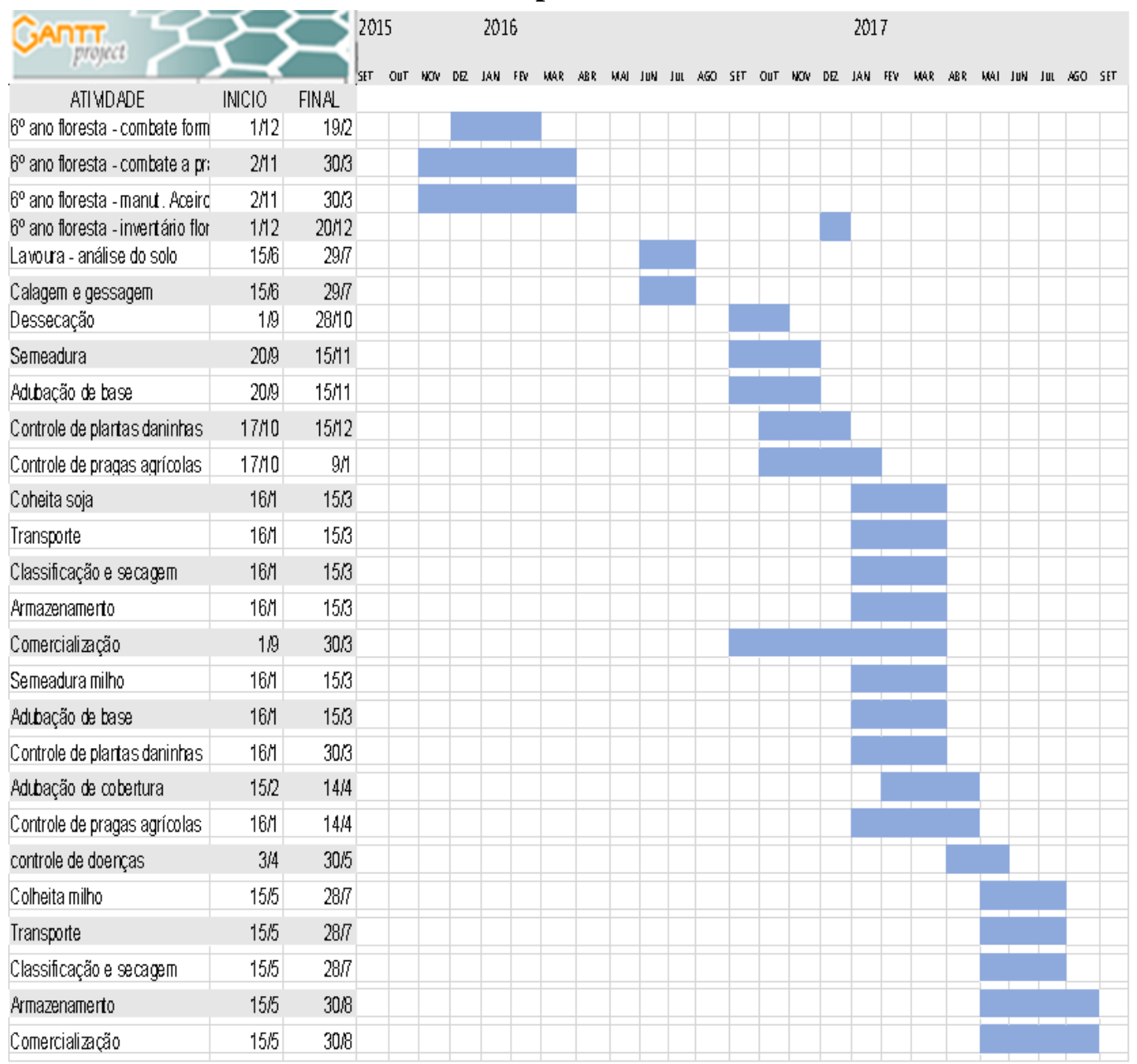

Fonte: Elaborado pelos autores (2020). 
O Gantt integrado ilustra o intervalo de dois meses entre processos da lavoura e da floresta, e diversas sobreposições de atividades entre os processos produtivos. O processo produtivo integrado inicia anualmente em junho com a preparação do solo para lavoura (análise do solo, aquisição de insumos, contratação de pessoal e investimento, e manutenção de armazenamento, máquinas e equipamentos). Na sequência, é realizada a semeadura da soja que dura três meses. Posteriormente, na fase dos tratos culturais, ocorrem a adubação e o controle de plantas daninhas e pragas, que encerram pouco antes do início da colheita. Durante a colheita são realizadas dessecação, transporte, classificação e armazenagem dos grãos. A comercialização do grão inicia-se antes do plantio e termina após a colheita.

A semeadura do milho é realizada simultaneamente à colheita da soja na mesma área produtiva: a plantadeira com milho segue atrás da colheitadeira de soja. A adubação do milho é realizada junto com a semeadura e com os tratos culturais para plantas daninhas e pragas, e sua adubação de cobertura inicia e termina com dias de diferença. $\mathrm{O}$ controle de pragas inicia logo após a semeadura, e o controle de doenças ocorre na fase final de crescimento da planta e finaliza com a colheita, que dura aproximadamente quatro meses. O transporte, classificação, armazenamento e comercialização iniciam-se a partir do início da colheita. $\mathrm{O}$ milho permanece no armazém da propriedade até sua comercialização ou uso para o gado.

Na floresta, ocorrem atividades concomitantes: no pré-plantio são feitos limpeza da área e construção de carreadores (entre junho a setembro), georreferenciamento para análise do solo (entre agosto a setembro), preparo do solo, adubação e aplicação de calcário (entre agosto a novembro). No primeiro ano da floresta, ocorre aplicação de herbicida, combate a pragas e adubação simultâneos, capina e desrama. Nos anos seguintes, acontece combate a formigas e pragas, elaboração do inventário, manutenção de aceiros, aplicação de herbicidas, calcário e adubação. Entre o segundo e o terceiro ano, ocorre desrama, entre o quarto e o quinto ano, o seu desbaste, que é repetido no sétimo e oitavo, e finaliza com o corte $\left(12^{\circ}\right)$, quando é comercializado.

Neste cenário, observa-se a sobreposição de etapas nas atividades lavoura e floresta nos seguintes processos produtivos que demandam as mesmas máquinas e pessoal: a) combate às pragas e manutenção de aceiros da floresta, realizados no período de semeadura e de colheita da soja; b) combate às formigas da floresta (que se estende por quase todo o primeiro ano de implantação) simultaneamente ao coveamento para plantio, desinfecção de mudas, e plantio e replantio do eucalipto (que dura um mês) e coincide com a semeadura e parte dos tratos culturais do milho; c) semeadura da soja que coincide com adubação de base e manutenção de aceiros e combate às pragas na floresta; e, d) desbaste da floresta na época do controle de doenças e colheita do milho. Estas sobreposições ocorrem também no cultivo das lavouras de soja e milho entre as etapas de colheita, transporte e classificação e dessecação da soja, e a semeadura e adubação de base do milho. No final da colheita e do transporte do milho iniciam-se as análises de solo para a safra de soja do ano seguinte. $\mathrm{O}$ transporte começa quando o fluxo das atividades iniciais diminui. Neste contexto, as máquinas e o pessoal concorrem entre si, mas como nesta empresa rural cada atividade 
possui recursos independentes para cada atividade produtiva, a concorrência foi totalmente eliminada.

O delineamento do gráfico de Gantt integrado das safras de soja e de milho que se repetem anualmente e da floresta (cultura perene) revela as tarefas sobrepostas, mostrando o caminho crítico de cada atividade e entre elas, permitindo perceber a dependência entre tais processos e os gargalos na estrutura e na divisão das tarefas. Isto facilita o planejamento (carregamento, sequenciamento, programação) e o controle (mensuração, monitoramento, avaliação e intervenção) destas atividades individualmente e integradas.

\subsection{Planejamento da produção do SINPA}

A implantação do SINPA não foi planejada inicialmente. Dados levantados por uma consultoria agronômica apresentaram solo arenoso em determinada área da propriedade, surgindo o interesse de plantar floresta sem buscar referências sobre o processo de integração. Como experimento, em 30 hectares foram plantadas 52 espécies de eucalipto adensadas, escolhidas por uma assessoria especializada visando o mercado de lenha. Em 2010, foi implantada a floresta integrada, ampliada em 2012 com variedades adaptadas ao solo, concluindo a implantação da integração lavoura-pecuária-floresta.

Para a pecuária parece não haver planejamento, pois o gestor relatou somente que ao retirar o gado para plantar soja, não existe um local específico para a continuidade da criação, e os bovinos são alocados em uma área isolada da propriedade em questão.

As etapas do planejamento - carregamento, sequenciamento e programação - são realizadas no sistema integrado desta empresa rural como descrito a seguir.

$\mathbf{O}$ carregamento refere-se à capacidade de produção ou à quantidade de trabalho destinada à produção sem comprometer seu nível de serviço (SLACK; CHAMBERS; JOHNSTON, 2009). No SINPA, o carregamento consiste na capacidade produtiva da terra e a que nível se pretende ou se consegue elevá-la, potencializando o uso da mesma área de terra para alcançar objetivos de desempenho superiores, considerando tanto cada atividade produtiva isoladamente, como as atividades integradas. Diversos arranjos são possíveis em sistemas produtivos integrados com base nos objetivos de desempenho e estratégias. É fundamental considerar os recursos necessários, sua disponibilidade e necessidade de alocação, incluindo, por exemplo, análises de custo e benefício entre arrendar ou adquirir maquinário e terra.

Os critérios de prioridade estratégica desta empresa rural são rentabilidade, diversificação da renda e sustentabilidade. A lavoura é a principal atividade e a soja o principal produto deste SINPA. Os critérios usados no carregamento convergem com as prioridades estratégicas: a rentabilidade é buscada por mudas selecionadas de eucalipto e sementes mais produtivas de soja, além de tratos culturais personalizados para cada talhão, respeito à época do plantio e às necessidades do solo, além de boa comercialização. A diversificação da renda é obtida pelo aumento de safras anuais: milho, soja, pecuária e eucalipto, e a sustentabilidade mediante os benefícios governamentais de reposição florestal. 
Dos 3.025 hectares, a área destinada para o SINPA é de 2.146 hectares, dos quais 1.446 hectares à lavoura, 200 hectares à pecuária e 500 hectares à floresta. Neste sentido, pretende-se ampliar a integração, alterando tal carregamento. O carregamento da lavoura é realizado por assessoria agronômica, que realiza análise anual do solo e pesquisas frequentes sobre a melhor forma de rentabilizá-lo. Além disso, disponibiliza relatório sobre variedades e quantidade de insumos e projeção de colheita por talhão. Na floresta o carregamento foi feito pelo gestor em planilha (da Microsoft Excel).

Apesar de haver carregamento da área de terra para lavoura (por talhão) e floresta, e de insumos para lavoura, os relatórios agronômicos e a planilha de Excel não distribuem a carga de trabalho do pessoal e de maquinários para cada atividade, conforme sugerido por Slack, Chambers e Johnston (2009). Além disso, tal carregamento é feito isoladamente por cada atividade produtiva, o que pode limitar os ganhos de escala e onerar as operações produtivas de cada atividade e do sistema integrado, reduzindo sua margem. Um exemplo foi a aquisição de mesmo maquinário e contratação de pessoal exclusivos para cada atividade, sendo que o capital imobilizado poderia ser aplicado no custeio da safra, que envolve valores significativos, o que reduziria o pagamento de juros. Além disso, o carregamento da lavoura é terceirizado. Após definir a carga de trabalho é necessário estabelecer a sequência de execução.

O sequenciamento refere-se à ordem como os processos serão trabalhados (SLACK; CHAMBERS; JOHNSTON, 2009). Em sistemas integrados de produção agrícola, as atividades agricultura, pecuária e/ou floresta dividem recursos produtivos, ora terra, ora máquinas e/ou ora pessoas. Portanto, sequenciar suas atividades e tarefas se torna ainda mais necessário para a eficiência das operações produtivas isoladas e integradas, devido à concorrência entre si.

A empresa rural não carregou suas atividades produtivas de forma a compartilhar os mesmos recursos, já que investiu em maquinário e pessoal independente para cada atividade. Assim, com exceção da terra e recursos financeiros não há concorrência entre os demais recursos produtivos e, cada atividade sequencia suas atividades de forma isolada. A produção da lavoura é sequenciada pela consultoria agronômica. O gestor da floresta sequenciou no Excel as principais etapas a serem seguidas.

Existem diferenças entre as etapas sequenciadas para florestas na literatura (REMADE, 2003) em relação às etapas praticadas na empresa rural analisada, e delineadas no gráfico de Gantt. Pré-plantio, transporte, venda de crédito e reposição de carbono (ou seja, a pós-colheita) não foram mencionados. Foram adicionados no preparo do solo: georreferenciamento, conservação de estradas, limpeza da área e carreadores, combate à formiga, roçada em área total, transporte de pessoal/máquinas, aplicação de calcário e desinfecção de mudas. E, como tratos culturais: inventário florestal e manutenção de aceiros e prevenção. Considerando Araújo (2009), na lavoura, não foram mencionadas outras etapas do pré-plantio tendo sido acrescentada a análise de solo. Não foi citada adubação de superfície, dessecação de plantas invasoras, aragem, gradagem e subsolagem no preparo do solo, adubação de cobertura e foliar, como tratos culturais. Enquanto isso, não foram incluídos a destruição da soqueira, na colheita, e a liberação de vendas 
antecipadas, no pós-colheita. No milho, pré-plantio e preparo do solo são realizados com os da soja, antes da primeira safra e é acrescentada a dessecação pós soja (ou seja, o preparo do solo) na entre safra. A prática observada atendeu ao semeio e aos tratos culturais.

Embora os gestores possuam formas diferentes e isoladas de sequenciar a produção, a ordem de etapas do processo produtivo é formalizada na floresta, parcialmente na lavoura, sendo a última priorizada, o que atende parcialmente ao requerido por Slack, Chambers e Johnston (2009). Demandas concorrentes foram suprimidas pela duplicidade de pessoal e maquinário, o que reduz os impactos do não sequenciamento exato e integrado das atividades produtivas.

A programação da produção consiste na atividade que produz uma tabela de tempos detalhados mostrando quando atividades devem iniciar e terminar (SLACK; CHAMBERS; JOHNSTON, 2009). No SINPA, a produção é agregada e gera multiproduto (OSAKI, 2012), envolvendo processos produtivos diferentes, cujas etapas podem requerer execução de forma intercalada, exigindo assim uma programação integrada. Programá-las de forma integrada exige detalhar os recursos a serem alocados e em quais momentos, sua competição para prever necessidade de arrendá-los ou adquiri-los, e seus impactos nos resultados, revelando maior ou menor elasticidade para a negociação da safra.

$\mathrm{Na}$ lavoura, a consultoria agronômica elabora e disponibiliza ao gestor a programação de cada safra em cronograma por talhão no qual constam: datas de início de plantio das variedades de soja e milho, previsão da aplicação de defensivos e da colheita, especificados e quantificados, que é repassado ao gerente de campo da lavoura. Não é programada formalmente a distribuição de maquinário e pessoal pelo gestor ou sua consultoria, cuja destinação acontece sem qualquer previsão, sendo a demanda observada naturalmente durante a execução. Logo, o pré-plantio, preparo do solo e pós colheita da lavoura não são programados e não estão formalizados.

A programação da floresta foi realizada antes do plantio pelo gestor com base na sua experiência em uma empresa de reflorestamento, com atividades mensais formalizadas do primeiro ao $12^{\circ}$ ano, utilizando uma planilha no Excel, desde o plantio do eucalipto até sua comercialização. No pré-plantio, plantio e tratos culturais, a programação revela mês/ano e quantidade de hectares das atividades, mas não detalha datas/períodos de aplicação de insumos, pessoal e maquinário. Na colheita, apresenta tamanho e espessura adequados e mês/ano para iniciar o corte. Porém, a pós colheita não foi programada.

Mesmo programados, em caso de concorrência de recursos, a lavoura possui prioridade, por exigir maior rigor na data de plantio e de colheita e no controle de pragas, por possuir custos altos de manutenção, e por gerar produtos responsáveis pela sobrevivência do negócio.

Comparando as etapas da lavoura desenvolvidas pela empresa no gráfico de Gantt e as apresentadas na literatura, nota-se divergência nas etapas seguidas e em sua quantidade. Apesar de apresentar data de início e fim do semeio, tratos culturais e colheita, convergindo ao preconizado por Slack, Chambers e Jhonston (2009), não há programação no préplantio, preparo do solo e pós colheita. Na floresta, as etapas também divergem da literatura e não apresentam datas específicas de início e fim das atividades, somente meses de cada 
ano. Neste caso, as datas são estimadas, dependendo de fatores incontroláveis como clima e mercado e mais controláveis como incidência de pragas e ervas daninhas e do desenvolvimento da planta ou animal, o que enfatiza a importância de programar todas as etapas, e não o contrário (que é praticado no caso estudado). Mesmo considerando certa margem de erro ou flexibilidade para contornar as peculiaridades próprias da produção no setor, destacadas por Buanain (2007), a programação agropecuária precisa ser realizada.

\subsection{Controle da produção do SINPA}

O controle efetivo da produção depende, em grande parte, do planejamento produtivo realizado (LOPES et al., 2012), já que corresponde ao acompanhamento do plano, ou seja, sua mensuração, monitoramento, avaliação e intervenção (SLACK; CHAMBERS; JOHNSTON, 2009). Em SINPAs, o controle da produção possui maior relevância devido à sobreposição de atividades produtivas e, consequente, competição pelos mesmos recursos. Além do acompanhamento do plano, pode amenizar impactos naturais imprevisíveis e/ou incontroláveis, como alterações climáticas, pragas, questões mercadológicas, entre outras especificidades da produção agrícola. O controle inicia-se pela medição.

A mensuração da produção é a parte do controle que combina sistematicamente ferramentas e/ou métricas utilizadas para qualificar e quantificar a eficiência e/ou eficácia de uma ação (NEELY; GREGORY; PLATTS, 1995), devendo assim ser registrada. (SLACK; CHAMBERS; JOHNSTON, 2009). No SINPA, a mensuração possibilita calcular resultados como produtividade, rendimento, capacidade produtiva, entre diversos indicadores de desempenho, por talhão e/ou por espécie cultivada/criada e/ou por tratos/tecnologias adotados, por atividade produtiva e/ou no seu conjunto, entre outros. Essa mensuração subsidia a análise de custo e benefício, e a tomada de decisões dos gestores.

A empresa rural em questão mede o desempenho em todas as etapas do processo produtivo da lavoura. Utiliza do pré-plantio ao semeio, o indicador capacidade do solo: a análise do solo aponta características que indicam sua capacidade produtiva, que embasa a definição dos tratos culturais para mantê-la ou aumentá-la. Na colheita e pós colheita, utiliza o indicador rentabilidade, calculado pela quantidade de sacas colhidas por hectare por safra (resultados da colheita e do transporte). Além disso, usa a relação entre o lucro e o investimento realizado pela lavoura a cada safra (comercialização). Para medir a produção da atividade florestal o gestor da integração utiliza os indicadores de capacidade nas etapas de pré-plantio até o semeio, e de rentabilidade na colheita, cujas fórmulas registradas em planilha não foram disponibilizadas. Não foi informado também o indicador do pós-colheita. A medição desses indicadores é realizada pelas variáveis: saída e entrada de recursos financeiros, sendo consideradas como saída: compras de insumos, adubos, mão de obra contratada e despesas diversas, e como entrada as vendas realizadas. A cada safra 
todas as entradas e saídas são registradas em planilhas e repassadas ao sistema de informações informatizado Consisa ${ }^{1}$.

Embora não tenham detalhado as ferramentas usadas para coletar os dados em nenhuma etapa dos processos produtivos, a mensuração realizada neste SINPA combina os indicadores de desempenho capacidade e rentabilidade (métricas) a cada safra em planilhas e em sistema (sistemática), para qualificar e quantificar a eficiência e/ou eficácia das lavouras e da floresta, o que converge com o preconizado por Neely, Gregory e Platts (1995) e Slack, Chambers e Johnston (2009). A escolha destes indicadores parece bastante adequada: a capacidade devido ao princípio dos sistemas integrados de produção agrícola potencializarem o uso da terra e dos demais recursos produtivos (NEELY; GREGORY; PLATTS, 1995, GASPARINI; COSTA; SZNITOWSKI, 2018), e a rentabilidade em função de avaliar o resultado final da gestão, e não somente a produtividade, que pode exigir investimentos tão altos que reduzam a rentabilidade, e comprometam a sobrevivência do negócio (OSAKI, 2012).

O monitoramento é o acompanhamento sistemático dos registros do desenvolvimento da atividade produtiva (SLACK; CHAMBERS; JOHNSTON, 2009). No SINPA, tais informações subsidiam decisões para a safra, considerando fatores climáticos e de mercado. Isto permite ajustes durante a safra atual, relevante pela concorrência de recursos e alterações da execução do plano em função de especificidades da produção agrícola não controláveis; e após a safra, comparando resultados para aprimorar o planejamento de safras futuras.

Nesta empresa rural, o monitoramento da lavoura é realizado pelo seu gerente de campo com periodicidade variada conforme a etapa do processo produtivo: diariamente do pré-plantio ao semeio e semanal nos tratos culturais, e não é realizado na colheita e póscolheita. É registrado manualmente em cadernos de campo e repassado ao sistema Consisa. O monitoramento da floresta é realizado pelo sócio e pelo gerente de campo, diariamente nas etapas de pré-plantio ao semeio, semanalmente nos tratos culturais, e semestralmente do $5^{\circ}$ ao $12^{\circ}$ ano na colheita, sendo os dados registrados manualmente em folhas individuais e depois repassados ao Consisa. Conforme sugerido por Slack, Chambers e Johnston (2009), o monitoramento da lavoura e da floresta e seu registro possuem responsáveis que o realizam com periodicidades definidas.

Depois de uma operação ter seu desempenho medido, é necessário julgá-lo, o que caracteriza a avaliação de desempenho da produção, que precisa ser realizada constantemente para que a intervenção e os ajustes sejam feitos conforme a necessidade (SLACK; CHAMBERS; JOHNSTON, 2009). No SINPA, avaliar o desempenho possibilita saber se a empresa está alcançando os objetivos propostos em cada atividade e na integração, e sua evolução ou involução em relação a anos anteriores ou em relação a outras culturas, padrões ou parâmetros, permitindo refletir se as práticas adotadas, as tecnologias implantadas e os métodos utilizados estão sendo efetivos.

1 O Consisa é um sistema de contabilidade completo para gerenciar rotinas e análise de resultados (CONSISA.COM.BR). 
A avaliação da lavoura é realizada nesta empresa rural no final da primeira e da segunda safra pelo gerente de campo da lavoura, que compara os resultados registrados na safra atual com os resultados da safra do ano anterior e algumas vezes de anos anteriores, destacando pontos de melhorias a serem considerados na próxima safra. Na floresta, é realizada com base em relatórios passados de um a três anos, desta e de outras empresas rurais, oriundos de relatórios gerados por um sistema informatizado de uma empresa de reflorestamento.

Entre os padrões de desempenho para avaliar os resultados histórico, alvo, concorrência e absoluto (SLACK; CHAMBERS; JOHNSTON, 2009), a empresa utiliza o padrão histórico ao comparar seus resultados atuais com resultados próprios de anos anteriores e identifica desvios na lavoura e na floresta separadamente. Na floresta, usa também o padrão concorrência por comparar seus dados com os de outros produtores, o que pode ser considerado um diferencial.

A intervenção compreende ajustes para que a operação atinja os objetivos estabelecidos pelo plano inicial, e a decisão corresponde ao momento propício para que essa intervenção ocorra (SLACK; CHAMBERS; JOHNSTON, 2009). No SINPA, decisões e intervenções devem considerar seus impactos nos demais processos produtivos e seus resultados globais, visando otimizar o sistema integrado, o que exige visão sistêmica da produção e de seus resultados. Assim como em sistemas convencionais, devem ocorrer sempre que for detectado desvio na avaliação, seja derivado de agentes incontroláveis ou controláveis. As decisões devem considerar a principal atividade produtiva ou reduzir ao máximo os impactos negativos na produção e nos resultados totais.

$\mathrm{Na}$ empresa rural analisada, quando surgem imprevistos durante a atividade da lavoura, o gerente de campo possui autonomia para solucionar imprevistos, ou seja, para decidir e intervir a qualquer tempo e independentemente da gravidade da ocorrência. As decisões se balizam na proteção da principal atividade, no caso, a lavoura de soja, ou em reduzir ao máximo os impactos negativos na produção.

Os ajustes realizados concretizam a intervenção conforme definida por Slack, Chambers e Johnston (2009). Neste empreendimento rural o gerente de campo possui autonomia para intervenção. Se por um lado sua autonomia decisória agiliza e minimiza consequências negativas em decisões rotineiras, imediatas e/ou esperadas, por outro lado, talvez o gerente nem sempre possua todas as informações para tomar decisões não programadas, mediatas ou improvisadas. Seria importante definir competências para a tomada de decisão por gravidade ou tipo de decisão, e o gestor participar com o gerente de campo quando necessário (OSAKI, 2012, LOPES et al., 2012). Para isto, o gerente de campo precisa possuir clareza quanto a cada tipo de decisão, se possui autonomia ou se deve reportá-la ao gestor.

\section{Conclusão}

Este estudo investigou como um sistema integrado de produção agrícola é planejado e controlado em uma empresa rural mato-grossense, considerada referência por produtores 
da região em questão. A análise incluiu compreender a prática do PCP em SINPA, identificando ganhos e tecnologias deste sistema integrado e do sistema convencional anteriormente aplicado.

A adesão ao SINPA exigiu adoção de tecnologias não usadas no sistema convencional na lavoura, aumentando a produtividade média de $22 \%$ na soja e de $25 \%$ no milho. A floresta não apresentou mudança de tecnologia, variação nos custos e no valor do produto nos dois sistemas, mas no sistema integrado implantou variedades de eucalipto superiores testadas no convencional e obteve incentivos fiscais. Os maiores obstáculos da implantação foram a falta de preparo da equipe e dificuldades no planejamento e no escalonamento das atividades produtivas.

Embora a empresa rural pesquisada possua ILPF e conte com consultorias agronômicas e de financiamento, a pecuária não é planejada nem controlada, e o planejamento da lavoura e da floresta são realizados separadamente. O carregamento considera apenas o fator terra em ambos, e insumos na lavoura, não sendo realizado para pessoas e maquinário. Além disso, na lavoura, é terceirizado à consultoria agronômica. $\mathrm{O}$ sequenciamento é formalizado na floresta e parcialmente na lavoura. Em ambos, as etapas seguidas divergem das apresentadas na literatura, inclusive em quantidade. Na lavoura, há programação do semeio, tratos culturais e colheita, e não do pré-plantio, preparo do solo e pós colheita. Na floresta, não são detalhadas datas das atividades, apenas meses/ano. Mesmo considerando certa flexibilidade devido às suas peculiaridades produtivas, a programação agropecuária precisa ser realizada.

A mensuração da lavoura e da floresta combina indicadores de desempenho capacidade e rentabilidade nas diferentes etapas, a cada safra, que parecem adequados ao sistema integrado (capacidade) e ao resultado da gestão (rentabilidade). O monitoramento é realizado por gerentes de campo com periodicidades variadas nas etapas da produção, e registrado manualmente em cadernos de campo e repassado a sistema. A avaliação de ambas é realizada pelos gerentes de campo: a da lavoura ao final das safras pelo padrão histórico, e a da floresta usando padrões histórico de um a três anos e o de concorrência. A intervenção é realizada imediatamente pelo gerente de campo com total autonomia, não havendo distinção de decisão a reportar ao gestor.

A falta do PCP integrando as atividades do SINPA desta empresa rural não permitiu obter os ganhos preconizados de otimização dos recursos de produção. O gráfico de Gantt integrado revelou a não competição de atividades e a não concorrência de pessoal e maquinário, já que foram adquiridos maquinários e contratado pessoal exclusivos para cada atividade da integração, o que pode gerar ociosidade na utilização e imobilizar mais capital do que o necessário, comprometendo as margens de retorno do negócios.

A principal limitação do estudo foi a não resposta referente a atividade pecuária, o que impossibilitou análise integrada do PCP da ILPF e a apresentação de um gráfico de Gantt integrado para ILPF.

Contudo, esse estudo contribui ao apresentar o gráfico de Gantt integrado delineado para lavoura e floresta desta empresa rural como ferramenta para auxiliar gestores a aprimorarem suas ações, considerando os recursos envolvidos nos três processos 
produtivos (a saber: lavoura-pecuária-floresta), e no entendimento para a realização do carregamento, do sequenciamento e da programação da produção, além de indicadores de desempenho e suas características de monitoramento, avaliação, decisão e intervenção para controle das atividades, de forma isolada e integrada, inovando sua gestão.

Se por um lado os resultados indicam o não uso do gráfico de Gantt, mesmo tendo sido adaptado pela EMBRAPA para fins de PCP da ILPF, por outro lado, denota a sua necessidade e importância no contexto em questão. Tais resultados sugerem que sistemas integrados de produção agrícola não possuem gestão integrada, ou seja, integram a produção, mas não sua gestão, o que pode ser atribuído às consultorias no agronegócio atuarem apenas no âmbito agronômico e não em gestão, devido à falta de conhecimento e/ou pessoal capacitado para atuar na área.

Para futuros estudos esta análise pode subsidiar evidências para planejamento e controle de produção (PCP) e para gerar outros instrumentos gerenciais de sistemas integrados baseados em processos, que instrumentalizem a gestão de produtores agropecuários, permitindo capacitar gestores e operadores das empresas a elaborar seus PCPs de forma adequada e integrada para potencializar os benefícios da implantação do sistema e seu controle.

É importante destacar o trabalho da EMBRAPA com ênfase em técnicas agronômicas e sua iniciativa de proposição do gráfico de Gantt adaptado para a ILPF, que evidencia a necessidade da gestão e do uso de tecnologias de gestão administrativas. Daí, a relevância dos aspectos voltados à gestão econômica em um contexto no qual a busca pela rentabilidade parece estar associada apenas à produtividade, desconsiderando a gestão de recursos e de processos que podem gerá-la, além de aprimorar tal sistema produtivo estratégico ao desenvolvimento rural e do agronegócio.

\section{Referências}

ARAUJO, M. J. Fundamentos de agronegócio. 1 ed. São Paulo: Atlas, 2003.

BALBINO, L. C.; CORDEIRO, L.A.M.; SILVA, V. P. da; MORAES, A. de; MARTÍNEZ, G.B.; ALVARENGA, R.C.; KICHEL, A.N.; FONTANELI, R.S.; SANTOS, H. P. dos; FRANCHINI, J.C.; GALERANI, P.R. Evolução tecnológica e arranjos produtivos de sistemas de integração lavoura-pecuária-floresta no Brasil.

Pesquisa agropecuária brasileira. Brasília, v. 46, n.10, p. i-xii, outubro 2011. Print version ISSN 0100-204X. On-line version ISSN 1678-3921. DOI: http://dx.doi.org/10.1590/S0100-204X2011001000001

BUAINAIN, M. Modelo e principais instrumentos de regulação setorial: uma nota didática. In: RAMOS, P. Dimensões do agronegócio brasileiro: políticas, instituições e perspectivas. Brasília, DF: MDA, p. 53-92, 2007. Disponível em: http://livros01.livrosgratis.com.br/md000005.pdf. Acesso em: 02 fevereiro de 2016. 
BUNGENSTAB, J. D. Sistemas de integração lavoura pecuária floresta - a produção sustentável. EMBRAPA gado de corte. 2 ed. Brasília, DF, p.79-85, 2012. ISBN 978-857035-110-4.

BRASIL. MINISTÉRIO DA AGRICULTURA, PECUÁRIA E ABASTECIMENTO. Interação lavoura, pecuária e floresta. versão online. Disponível em:

http://www.agricultura.gov.br/ desenvolvimento-sustentavel/integracao-lavoura-pecuariasilvicultura. Acesso em: 20 maio 2016.

CALLADO, Antonio Andre Cunha. Agronegócio. 3 ed. São Paulo: Atlas, 2011.

CHASE, Richard. B.; AQUILANO, Nicholas. J.; JACOBS, F. Robert. Administração da produção e operações para vantagens competitivas. 11. ed. Porto Alegre: McGraw Hill, 2006. ISBN: 9788586804694

CONSISA SISTEMAS. Sistemas de contabilidade. Disponível em: https://consisa.com.br/solucoes/solucoes-escritorios-contabeis/ Acesso em 6 JUl. 2020.

CURY, A.. Organização e métodos: uma visão holística. 9. ed. São Paulo: Atlas, 2017. ISBN 978-85-97-01002-2.

DAVIS, J. H.; GOLDBERG, R. A. A concept of agribusiness. Boston: Harvard University, p.135, 1957.

JUNQUEIRA, M. N.; SALOMÃO, S.; QUEIROZ, G. A.; IANNONI, J. R. Encontro Nacional de Engenharia de Produção, Fortaleza - CE, Brasil, 2015.Utilização da ferramenta gráfico de Gantt no processo produtivo de uma empresa de equipamentos médicos de Franca-SP. XXXV ENEGEP, p. 4-5, 2015.

EMPRESA BRASILEIRA DE PESQUISA AGROPECUÁRIA. Pesquisa mostra avanço na adoção da ILPF por produtores mato-grossenses. EMBRAPA, 2016, versão online. Disponível em https://www.embrapa.br/busca-de-noticias//noticia/18432332/pesquisa-mostra-avanco-na-adocao-da-ilpf-por-produtores-matogrossenses. Acesso em: 24 abril 2019.

. Integração Lavoura Pecuária Floresta - ILPF. 2017, versão online. Disponível em: https://www.embrapa.br/tema-integracao-lavoura-pecuaria-florestailpf/nota-tecnica. Acesso em: 20 abril 2019.

VI Congresso brasileiro sobre ciclo de vida. Alocação de impactos em sistemas multiprodutos: integração lavoura, pecuária e floresta. Organização: IBICT e ABCV, Cooperação: UFSCar Brasília, p. 226-244, 2018.

. Jornal Eletrônico da ILPF. Ano 10. ed. 59, 2019. Disponível em: http://boletimilpf.cnpms.embrapa.br/noticia.php?ed=NTk=\&id=MzIw. Acesso em: fevereiro 2019. 
GASPARINI, L. V. L.; COSTA, T. S.; HUNGARO, O. A. L.; SZNITOWSKI, A.M.; VIEIRA FILHO, J.E. R. Sistemas integrados de produção agropecuária e inovação em gestão: estudos de casos no Mato Grosso. INSTITUDO DE PESQUISA ECÔNOMICA APLICADA. Ministério do Planejamento, Desenvolvimento e Gestão. 2017. n 2296, Brasília: Ipea, 10-18, 2017. ISSN 1415-4765.

GASPARINI, L. V. L.; COSTA, P. S.; SZNITOWSKI, A. M. Planejamento e controle da produção em sistema integrado de produção agropecuária: estudo exploratório no Mato Grosso. ENCONTRO NACIONAL DOS CURSOS DE GRADUAÇÃO EM ADMINISTRAÇÃO, XXIX ENANGRAD Anais eletrônicos, 29. São Paulo, FECAPE, p. 4-15, 2018. Disponível em http://2018.enangrad.org.br/pdf/2018_ENANGRAD493.pdf. Acesso em: fevereiro 2019.

HIRAKURI, M. H.; DEBIASI, H.; PROCÓPIO, S. O.; FRANCHINI, J. C.; CASTRO, C. Sistemas de Produção: conceitos e definições no contexto agrícola. Londrina: EMBRAPA Soja, v. 14, p.12-22, 2012.

INSTITUTO MATOGROSSENSE DE ECONOMIA AGROPECUÁRIA - IMEA. Mapa de Macrorregiões do IMEA. 2017, p. 1-8. Boletim informativo. Disponível em: http://www.imea.com.br/imea-site/view/uploads/metodologia/justificativamapa.pdf. Acesso em: 16 de maio 2018.

IKERD, John E. Center for Sustainable Agriculture, University of Missouri-Columbia, Columbia, MO 65211, USA. Agriculture, Ecosystems and Environment, 46, p. 147160. Elsevier Science Publishers B.V., Amsterdam. 1993. DOI: https://doi.org/10.1016/0167-8809(93)90020-P.

LOPES, F. F.; NEVES, M. F.; BARA, J. G.; TROMBIN, V. G.; LUPINACCI, A. V.; SIMPRINI, E. S.; TIBERIO, M. A. Agro Performance: um método de planejamento e gestão estratégica para empreendimentos Agro visando alta performance. São Paulo: Atlas, 2012.

NEELY, A.; GREGORY, M.; PLATTS, K. Performance measurement system design: A literature review and research agenda. International Journal of Operations \&

Production Management, 1995, v. 15, n. 4, p. 80-116. DOI:

https://doi.org/10.1108/01443579510083622.

NOBRE, M. M.; OLIVEIRA, I. R. de. Editores técnicos. Agricultura de baixo carbono: tecnologias e estratégias de implantação. Brasília, DF: EMBRAPA, p. 178-180, 2018.

OSAKI, M. Gestão financeira e econômica da propriedade rural com multiproduto. In OSAKI, M. Gestão na propriedade rural ou fazenda. Tese. (Tese de doutorado). Universidade Federal São Carlos, p. 41 - 65, 2012.

REMADE. Produtividade do plantio ao transporte. Revista da Madeira. ed. n. 77. 2003. Disponível em http://www.remade.com.br/br/revistadamadeira_materia.php?num=468\&subject=Silvicul 
tura\&title=Produtividade $\% 20$ do $\% 20$ plantio $\% 20 \mathrm{ao} \% 20$ transporte. Acesso em: 10 junho 2015 .

RUSSELLE, M. P.; ENTZ, M. H.; FRANZLUEBBERS, A. J. Reconsidering Integrated Crop-Livestock Systems in North America. Agronomy Journal, v. 99, march-april, 325-334, 2007. Symposium Papers. a American Society of Agronomy 677 S. Segoe Rd., Madison, WI 53711 USA. DOI:10.2134/agronj2006.0139.

SLACK, N.; JOHNSTON, R.; CHAMBERS, S. Administração da Produção. 2.ed. São Paulo: Atlas, 313 p., 2009.

SULC, R. M.; TRACY, B. F. Integrated Crop-Livestock Systems in the U.S. Corn Belt. Agronomy Journal, v. 99, march-april, p. 335-345, 2007. Symposium Papers. ${ }^{\text {a }}$ American Society of Agronomy 677 S. Segoe Rd., Madison, WI 53711 USA. DOI: 10.2134/agronj2006.0086.

YIN, R. K. Estudo de caso: planejamento e métodos. Tradução Ana Trorell; revisão técnica Cláudio Damacena. 4 ed. Porto Alegre: Bookman, 2010. 